\title{
Квантовый выход двусторонних солнечных элементов типа НІТ
}

\author{
() А.В. Ермачихин, Ю.В. Воробьев, А.Д. Маслов, Е.П. Трусов, В.Г. Литвинов \\ Рязанский государственный радиотехнический университет им. В.Ф. Уткина, \\ 390005 Рязань, Россия \\ E-mail: al.erm@mail.ru
}

Поступила в Редакцию 15 апреля 2020 г.

В окончательной редакции 27 апреля2020 г.

Принята к публикации 27 апреля 2020 г.

Показано, что использование обеих сторон солнечных элементов, созданных с использованием гетеропереходной технологии, позволяет повысить эффективность солнечных элементов. Различие при освещении лицевой и тыльной сторон связано с преобразованием синего участка спектра, что показано на примере спектральной дисперсии квантового выхода. Средняя разница между квантовым выходом для двух сторон составила $\sim 11 \%$. Плотность тока короткого замыкания для лицевой стороны при мощности солнечного спектра на уровне моря от 400 до 1100 нм равна $36.3 \mathrm{~mA} / \mathrm{cm}^{2}$, а для тыльной стороны $-32.7 \mathrm{~mA} / \mathrm{cm}^{2}$. Снижение составило $9.7 \%$.

Ключевые слова: солнечные элементы, гетеропереходы, квантовый выход, диффузионный потенциал, напряжение холостого хода, ток короткого замыкания.

DOI: 10.21883/FTP.2020.10.49944.9415

\section{1. Введение}

Солнечные элементы (СЭ) на основе гетеропереходов (heterojunction with intrinsic thin layer) [1] стремительно захватывают рынок солнечной энергетики (по данным компании Panasonic на апрель 2019 г. более 4 миллионов модулей только в Европе). Эта технология развивается уже сравнительно долгое время многочисленными исследователями по всему миру [2,3]. В начале своего существования рекорд эффективности таких устройств постоянно обновлялся, что обусловливало как повышение рентабельности, так и дополнительный рост интереса к этой технологии. Высокие темпы прироста коэффициента полезного действия в этот период объясняются повышением уровня технологии изготовления, совершенствованием методик осаждения, оптимизацией состава и структуры активных слоев, их толщины, улучшением качества электродов [4,5].

Однако сейчас тенденция к повышению эффективности СЭ сходит на нет. К примеру, в период с 1995 по 2000 гг. кпд гетеропереходных солнечных элементов вырос с 14 до 21\%, а в период с 2000 по 2010 гг. прирост составил всего $2 \%$. Текущий рекорд эффективности солнечного элемента составляет 26.7\% (Kaneka, 2017) [6,7] и 26.33\% (Kaneka, сентябрь 2016) [8,9] (предыдущий рекорд составлял $25.57 \%$ - Panasonic, апрель 2014 [10]). В обоих случаях повышение кпд объясняется повышением качества аморфных слоев, а также снижением сопротивления электродов. В ноябре 2019 г. Hanergy объявила, что ее центр исследований и разработок в Чэнду побил собственный рекорд по эффективности кремниевых гетеропереходов, достигнув 25.11\% для ,полноразмерного“ элемента размером $244 \mathrm{~cm}^{2}$ [11]. Это достижение превосходит предыдущий рекорд Hanergy в 24.85\% по ячейке аналогичного размера, установленный в августе
2019 г. [12], и приближается к рекорду эффективности ячейки, достигнутому на немного меньшей ячейке площадью $180 \mathrm{~cm}^{2}$ японским производителем Kaneka еще в 2017 году. Таким образом, за последние 19 лет прирост кпд составил всего 5.7\%. Это указывает на насыщение процесса повышения эффективности гетеропереходных солнечных элементов, хотя теоретический максимум $>30 \%$ ) еще не достигнут. Одним из способов увеличения эффективности преобразования солнечной энергии в электрическую является использование тыльной стороны СЭ [13]. Дополнительные носители будут генерироваться отраженным светом. В настоящее время оценка эффективности СЭ при облучении лицевой и тыльной сторон является актуальной задачей.

\section{2. Образцы и методы исследования}

Для исследования были выбраны структуры производственного качества, основанные на переходе $a-\mathrm{Si}: \mathrm{H}(n) / a-\mathrm{Si}: \mathrm{H}(i) / c-\mathrm{Si}(p) / a-\mathrm{Si}: \mathrm{H}(i) / a-\mathrm{Si}: \mathrm{H}\left(p^{+}\right)$[14]. Выбор типа слоев в СЭ внес особенности в строение контактов: использование аморфного кремния с дырочным типом проводимости привело к меньшему зазору между токосъемными контактами на тыльной стороне СЭ. Также на эффективность использования отраженного излучения влияет толщина базы СЭ. В данных образцах толщина слоя кристаллического кремния была 100 мкм. НІТ-структура выращена в НТЦ „Тонкопленочные технологии в энергетике“ Физикотехнического института им. А.Ф. Иоффе РАН (СанктПетербург, Россия).

Для нахождения диффузионного потенциала использовался метод измерения вольт-фарадных характеристик $(\mathrm{BФX).} \mathrm{Чтобы} \mathrm{производить} \mathrm{измерение} \mathrm{емкости} \mathrm{и} \mathrm{тока}$ 
при разных температурах, образец был помещен в криостат замкнутого типа Janis CCS-400/204N, термоконтроллер LakeShore 335 поддерживал необходимую температуру, а сами измерения происходили на RLC-метре Agilent E4980A. Измерение квантового выхода (EQE external quantum efficiency) осуществлялось путем сравнения токов с образца и эталонного фотодиода при их освещении монохроматическим светом:

$$
Q_{S C}=Q_{P D} \frac{I_{S C}}{I_{P D}},
$$

где $Q_{S C}$ - квантовый выход СЭ, $Q_{P D}-$ квантовый выход фотодиода ФДУК-100УТ, $I_{S C}$ - ток СЭ, $I_{P D}-$ ток фотодиода. Для измерения тока использовался пикоамперметр Keithley 6487, монохроматическое излучение получено при помощи монохроматора МДР-206 с набором фильтров. Измерение вольт-амперных характеристик (BAX) осуществлялось с помощью электрометра Keithley 6517B. Для исследования наличия глубоких энергетических уровней на границе интерфейса $a-\mathrm{Si}: \mathrm{H} / c-\mathrm{Si}$ применялась релаксационная спектроскопия глубоких уровней (РСГУ) [15].

\section{3. Эксперимент и анализ результатов}

Измерение ВФХ при комнатной температуре показало, что емкость образца в диапазоне частот от 100 Гц до 100 кГц совпадает с погрешностью $2.66 \%$, что близко к литературным данным ( 3\% по [16]), так что можно считать, что в данном диапазоне частот емкость СЭ не зависит от частоты измерительного сигнала. Построив зависимость $1 / C^{2}$ от напряжения (рис. 1), с помощью линейной аппроксимации было получено два участка и, соответственно, два значения общего диффузионного потенциала. Видно, что выбор области аппроксимации меняет полученное напряжение. Кривизну зависимости $1 / C^{2}$ можно интерпретировать как изменение эффективной площади поверхности на краю области пространственного заряда. Дело в том, что в исследуемом СЭ поверхность соединения текстурирована, и площадь поверхности устройства должна быть скорректирована с помощью коэффициента площади, который представляет собой увеличение площади поверхности, вызванное текстурированием. Этот фактор зависит от геометрии текстурированной поверхности, и его значение может находиться в диапазоне от 1.1 до 1.7 [17,18]. Однако эффективная площадь, рассматриваемая в измерениях ВФХ, зависит от приложенного напряжения. При малых напряжениях обратного смещения площадь образца близка к истинной площади текстурированной поверхности. В случае, когда применяются большие напряжения обратного смещения, увеличение поверхности, вызванное текстурированием, имеет тенденцию исчезать, и эффективная площадь приближается к площади образца с плоской поверхностью, как показано в работе [19] на текстурированных кремниевых солнечных элементах.

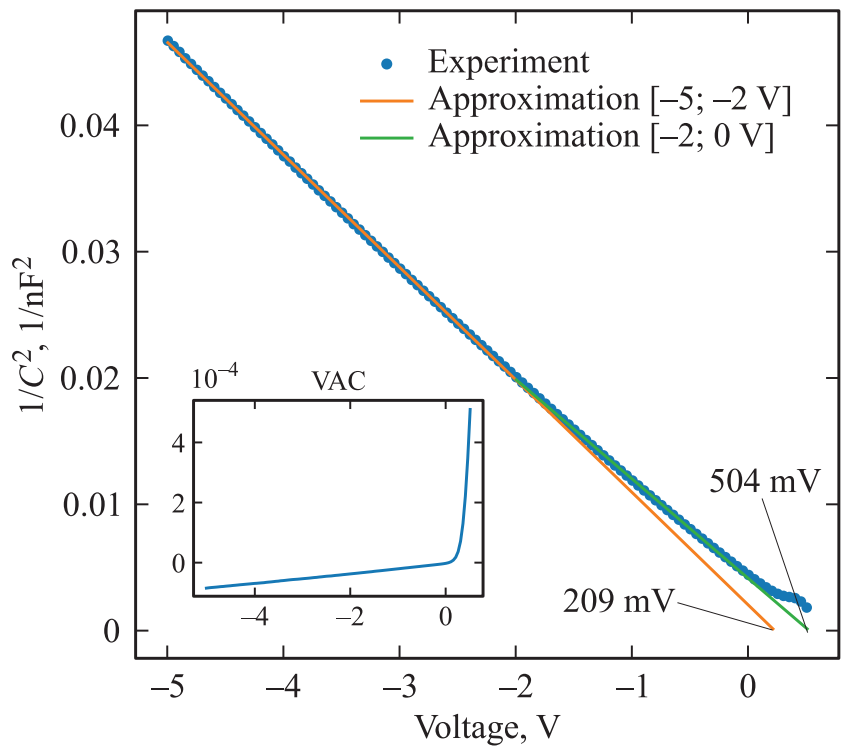

Рис. 1. Зависимость обратного квадрата емкости от напряжения. На вставке представлена ВАХ при комнатной температуре.

Уменьшение площади поверхности при высоких приложенных напряжениях можно объяснить, если принять во внимание ширину области обеднения в $c$-Si. Чем больше применяемое смещение, тем больше ширина истощения. Таким образом, модуляция ширины истощения, возникающая под воздействием измерительного переменного сигнала $30 \mathrm{MB}$, происходит дальше от текстурированной поверхности перехода, чем при небольшом смещении, и если предел области истощения лежит глубже в объеме, эффективная область меньше зависит от текстуры интерфейса [20].

В данной работе измерение ВФХ при комнатной температуре было необходимо для выбора режимов при температурных исследованиях. Так как при низких значениях напряжения смещения площадь образца близка к истинной площади, температурные измерения ВФХ проходили до $-2 \mathrm{~B}$. На вставке к рис. 1 представлена BAX при тех же условиях измерения, что и ВФХ.

При температурных измерениях были получены зависимости $C-\omega-U-T$. Для простоты восприятия зависимость емкости от температуры при разных частотах была взята для одного значения обратного смещения, равного -1 В (рис. 2). При других напряжениях смещения изменяются только значения емкости, а качественных изменений не происходит. Из графика видно, что существуют две области - квазистатическая и зависимая от частоты сигнала. Разница значений емкости при разных частотах при более низких температурах указывает на наличие переходных процессов в $a$-Si. $\mathrm{B}$ высокочастотном режиме слой $a-\mathrm{Si}: \mathrm{H}$ ведет себя как изолятор, и соответствующая емкость, таким образом, просто равна геометрической диэлектрической емкости. В низкочастотном режиме, когда щелевые состояния в 


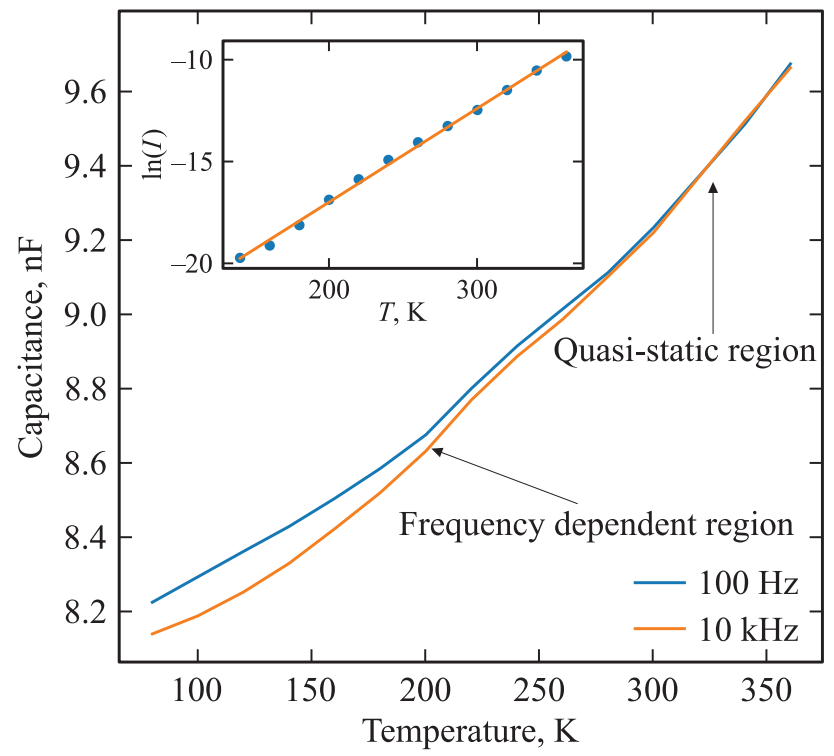

Рис. 2. Зависимость емкости от температуры при частотах 100 Гц и 10 кГц. На вставке представлена зависимость $\ln (I)$ от температуры.

$a-\mathrm{Si}: \mathrm{H}$ способны следовать за сигналом переменного тока, соответствующая емкость $a-\mathrm{Si}: \mathrm{H}$ очень велика по сравнению с емкостью $c$-Si. Это означает, что ширина слоя объемного заряда в $a-\mathrm{Si}: \mathrm{H}$ очень мала по сравнению с шириной в $c$-Si. C этой точки зрения система ведет себя как $n^{+}-p$-одностороннее соединение, и падением потенциала в аморфном слое можно пренебречь.

На вставке к рис. 2 показана зависимость натурального логарифма тока от температуры. Приведены как сами значения тока (символы), так и линейная аппроксимация (линии), которая наглядно показывает, что рост тока при увеличении температуры имеет экспоненциальную зависимость, что соответствует типичному $p-n$-переходу.

Температурные измерения значений емкости от напряжения смещения могут дать несколько значений диффузионного потенциала, так как в отличие от высоких температур (около комнатной и выше), при низких значениях температуры емкость зависит от частоты. Квадрат обратной емкости имеет линейные зависимости от напряжения смещения для разных частот. Тем не менее наклон и определяемое напряжение диффузионного потенциала получаются разными. Использование данных по емкости, полученных на низкой частоте, дает правильное значение для плотности легирования $c$ - $\mathrm{Si}$, в то время как значение, полученное из данных по емкости в высокочастотном режиме, является ошибочным, без учета тех энергетических состояний, которые не успевают перезарядиться вслед за изменением электрического поля переменного измерительного сигнала. Возможность получения диффузионного потенциала из зависимости квадрата обратной емкости от напряжения смещения, а также влияния частоты на кривую ВФХ более подробно описаны в работе [21]. Напряжения, получаемые при продлении аппроксимации обратного квадрата емкости до нуля, меняются от $786 \mathrm{MB}$ при $80 \mathrm{~K}$ до $400 \mathrm{MB}$ при $360 \mathrm{~K}$ (рис. 3) (более подробно зависимость показана на вставке к рис. 3 ).

Подобную температурную зависимость имеет и напряжение холостого хода $\left(V_{o c}\right)$ : с ростом температуры напряжение падает (рис. 4). При облучении светом определенной длины волны $V_{o c}$ имеет различные абсолютные значения (более подробно показано на рис. 5). При этом чем ниже длина волны света, тем меньше $V_{o c}$, что связано со спектральной чувствительностью образца. Из-за того, что в качестве источника белого света была

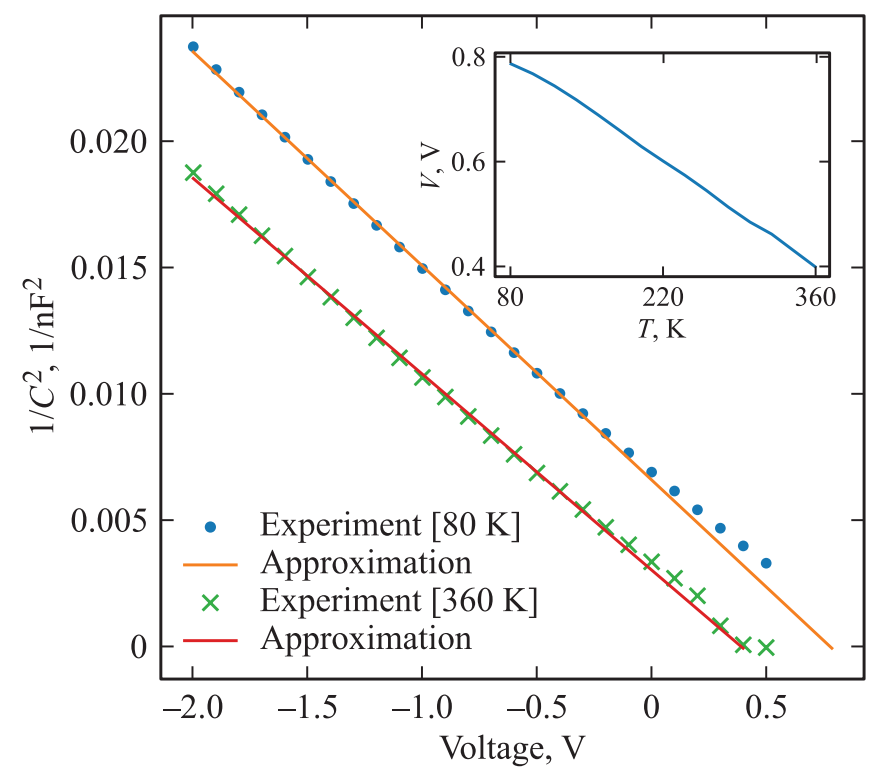

Рис. 3. Зависимость обратного квадрата емкости от напряжения смещения при температурах 80 и $360 \mathrm{~K}$. На вставке зависимость диффузионного потенциала от температуры.

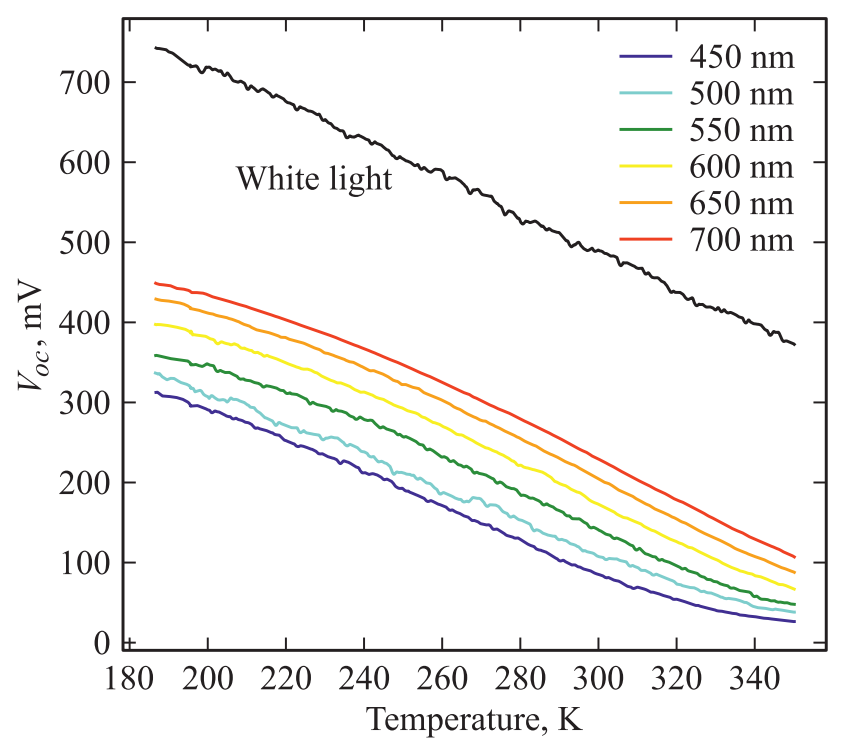

Рис. 4. Зависимость $V_{o c}$ от температуры на разных длинах волн при одинаковой мощности излучения и при белом свете. 


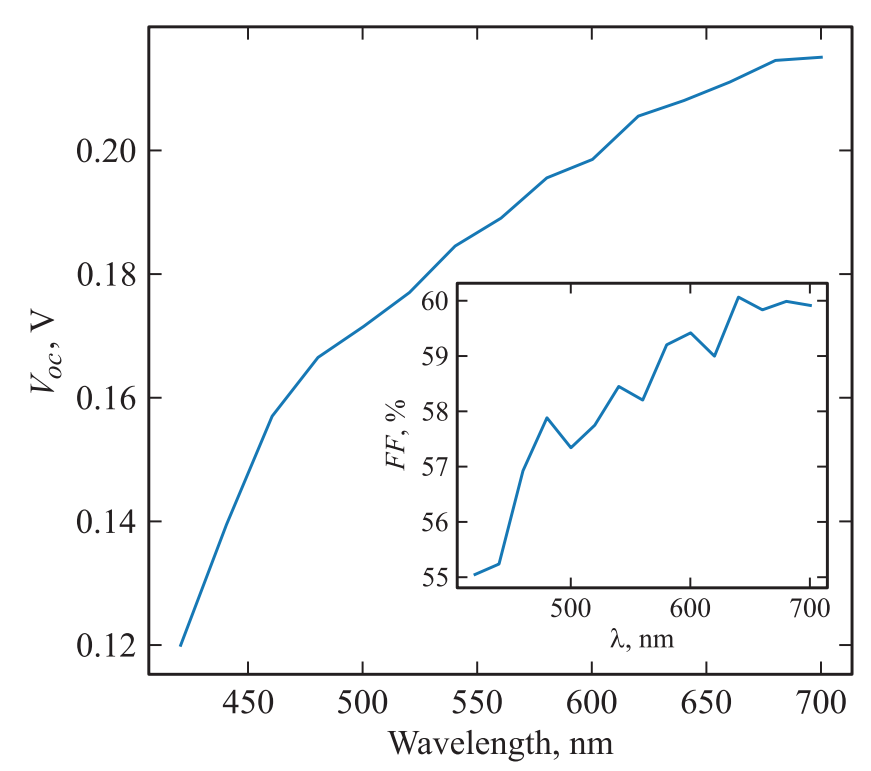

Рис. 5. Зависимость напряжения холостого хода от длины волны излучения. На вставке - фактор заполнения.

использована галогеновая лампа, величина интегральной составляющей напряжения имеет значительно большее значение, что обусловлено поглощением всего спектра света. Однако стоит отметить, что энергия в солнечном спектре распределена неравномерно от длины волны [22], а эксперимент проводился при одинаковой мощности излучения на всех длинах волн. Коэффициент корреляции Пирсона [23] температурного снижения диффузионного потенциала и напряжения холостого хода в диапазоне 200-340 K составил 0.9988. Снижение эффективности СЭ с ростом температуры [24] в основном связано с уменышением $V_{o c}$. Для НІТ данный негативный коэффициент несколько ниже, примерно $-0.29 \%$ на ${ }^{\circ} \mathrm{C}$. Температурный коэффициент обычных кристаллических кремниевых СЭ составляет от -0.4 до $-0.5 \%$ на ${ }^{\circ} \mathrm{C}[10]$. Для повышения эффективности СЭ необходимо уменьшить снижение $V_{o c}$ с ростом температуры. Если учесть корреляцию между снижением $V_{o c}$ и диффузионным потенциалом, то для повышения эффективности СЭ можно попытаться уменьшить снижение диффузионного потенциала с ростом температуры.

Самые большие значения измеряемого тока СЭ наблюдаются в диапазоне длин волн 420-700 нм. Измерение ВАХ происходило с шагом 20 нм (рис. 5). Для сравнения влияния квантов света разной частоты на структуру для всех длин волн была выбрана одинаковая мощность излучения 50 мкВт. Стоит отметить, что напряжение холостого хода и ток короткого замыкания сильно зависят от мощности излучения.

При комнатной температуре и в „темной комнате были получены значения квантового выхода для двух сторон СЭ (рис. 6). Анализ спектральной дисперсии квантового выхода показывает смещение линии роста поглощения излучения в область более длинных волн, примерно с 400 на 500 нм, при использовании тыльной стороны СЭ по сравнению с лицевой стороной. Кроме этого наблюдается общее снижение квантового выхода на всех длинах волн от 34 до $3 \%$, среднее снижение квантового выхода в диапазоне 400-1100 нм составило $10.85 \%$.

Если выразить плотность тока короткого замыкания СЭ через квантовый выход, то получим

$$
J_{S C}=\frac{e}{h c} \int \lambda Q(\lambda) S I(\lambda) d \lambda,
$$

где $J_{S C}$ - плотность тока короткого замыкания, $Q(\lambda)-$ спектральная дисперсия квантового выхода, $S I(\lambda)-$ мощность солнечного излучения на единицу площади на единицу спектральной полосы $\left[\mathrm{BT} \cdot \mathrm{M}^{-2} \cdot \mathrm{HM}^{-1}\right]$.

Вычисление интеграла производилось на основе значений спектра солнца AM1.5 стандарта ASTM G173-03 [25]. Плотность тока короткого замыкания для лицевой стороны при мощности солнечного спектра на уровне моря от 400 до $1100 \mathrm{Hм}$ равна $36.3 \mathrm{MA} / \mathrm{cm}^{2}$, а для тыльной стороны - $32.7 \mathrm{MA} / \mathrm{cm}^{2}$. Снижение составило $9.7 \%$. Сами значения токов совпадают с литературными данными [2,7]. На вставке к рис. 6 показано, как соотносятся между собой квантовый выход СЭ и солнечный спектр. Зависимость квантового выхода с лицевой стороны СЭ в области до 500 нм практически перекрывает солнечный спектр на уровне моря, в то время как квантовый выход с тыльной стороны делает это в среднем на 30\% менее эффективно. Это связано с поглощением в поверхностном слое СЭ. Известно, что синий отклик квантового выхода увеличивается с уменьшением толщины эмиттера [26,27]. С изменением толщины верхнего слоя квантовый выход изменяется

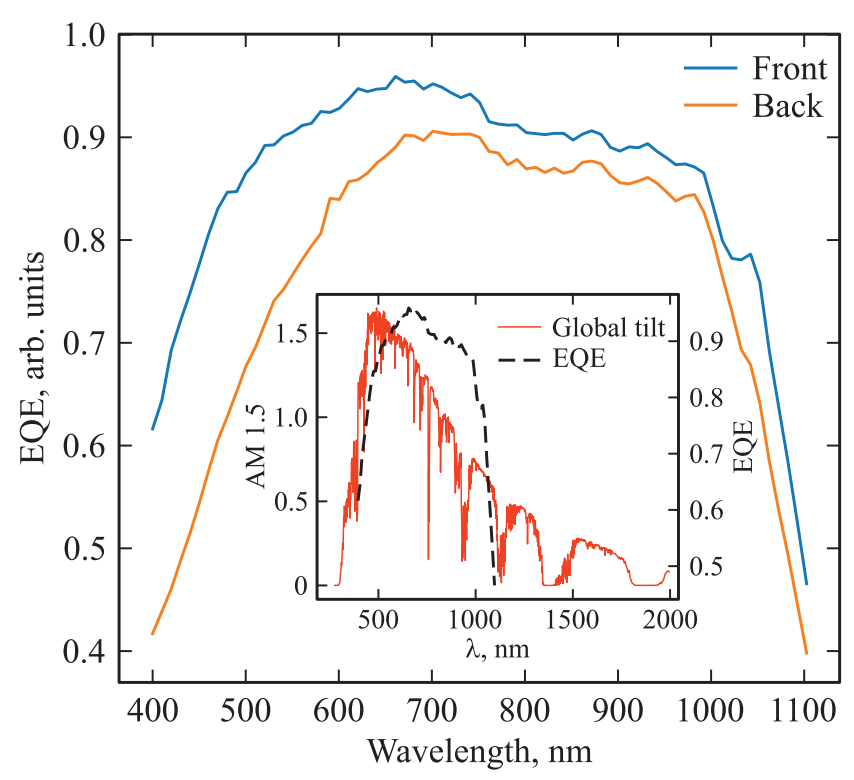

Рис. 6. Спектральная дисперсия квантового выхода для лицевой и тыльной сторон СЭ. На вставке показано как соотносятся между собой квантовый выход СЭ и спектр солнца АМ 1.5. 


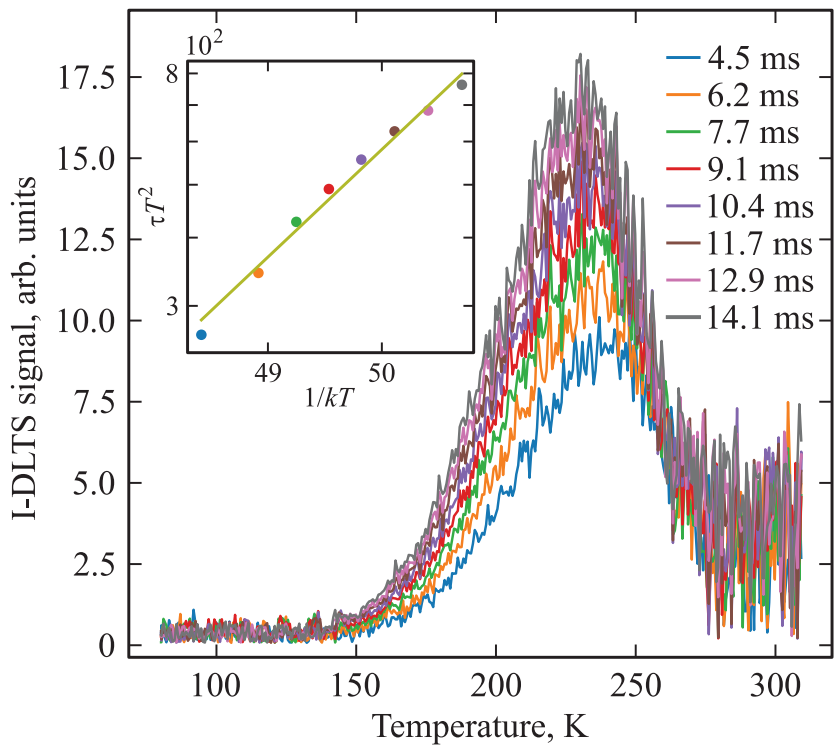

Рис. 7. РСГУ спектры для времени релаксации от 4.5 (нижний) до 14.1 мс (верхний). На вставке - прямая Аррениуса.

главным образом из-за оптического поглощения коротковолнового света на малом расстоянии от верхней поверхности СЭ. В работе [28] показано, что снижение квантового выхода происходит даже при незначительном росте толщины эмиттера. Также снижение значений квантового выхода на других длинах волн связано с большей концентрацией примеси в слое $a-\mathrm{Si}: \mathrm{H}\left(p^{+}\right)$, чем в слое $a-\mathrm{Si}: \mathrm{H}(n)$.

Исследование методом РСГУ (рис. 7) выявило наличие одного глубокого уровня. Время заполняющего импульса равнялось 1 мс, опустошающего - 100 мс, заполняющий импульс был равен $0 \mathrm{~B}$, опустошающий минус 1 В. Скорость нагрева была постоянна на всем температурном участке от 80 до $380 \mathrm{~K}$ и составляла $2 \mathrm{~K} /$ мин. С увеличением температуры происходит рост тока из-за увеличения тока утечки, поэтому спектры представлены на рис. 6 до $320 \mathrm{~K}$. По температурам максимумов для разных времен релаксации была построена прямая Аррениуса в координатах $\tau T^{2}$ от $1 / k T$.

Исследование ВФХ (рис. 1) показывает наличие нескольких областей изменения емкости, которое связано с текстурированием интерфейса. Для того чтобы захватить в область исследования этот участок, было выбрано такое напряжение обеднения, так как при небольшом обратном смещении граница ОПЗ проходит через текстурированный интерфейс. Энергия глубокого уровня, полученная по прямой Аррениуса, равна $455 \pm 30$ мэВ. В литературных данных $[29,30]$ имеется значение энергии активации примеси, равное 0.45 эВ. Контроль концентрации легирования $a-\mathrm{Si}: \mathrm{H}$ для получения подходящего уровня Ферми очень важен для изготовления СЭ с высокими характеристиками. Высокий уровень энергии позволяет подавить рекомбинацию интерфейса $a-\mathrm{Si}: \mathrm{H} / c-\mathrm{Si}$ и приводит к высокому значению напряжения холостого хода. Сам уровень связан с легирующей примесью для $p$-области [31]. Рост амплитуды пика РСГУ при увеличении времени релаксации указывает на перезарядку энергетических состояний на границе раздела аморфного и кристаллического кремния.

\section{4. Заключение}

Показано, что тыльная сторона СЭ может принимать активное участие в генерации носителей заряда. Квантовый выход при освещении лицевой стороны имеет большую составляющую на низких длинах волн в видимом диапазоне (синий свет), что связано с интенсивным поглощением в приповерхностном слое излучения с такими длинами волн. Общее снижение квантового выхода при использовании тыльной стороны связано с большим расстоянием в материале, которое необходимо преодолеть фотонам прежде, чем достигнуть ОПЗ. Разница между эффективностью при использовании лицевой и тыльной сторон СЭ составила 11\% для квантового выхода и $\sim 10 \%$ для плотности тока короткого замыкания. Это показывает, что использовать тыльную сторону для генерации носителей заряда отраженным излучением является хорошим способом повысить общую эффективность всей панели. Но реальный вклад в эффективность будет зависеть от мощности отраженного света, на что влияет множество параметров, которые невозможно сейчас оценить.

Найдена корреляция между температурными зависимостями диффузионного потенциала и напряжения холостого хода. Коэффициент корреляции Пирсона составил 0.9988, что очень близко к 1. Это указывает на то, что процессы, происходящие в СЭ с ростом температуры, которые влияют на данные параметры, взаимосвязаны между собой. Чтобы уменьшить негативное влияние температуры на снижение $V_{o c}$, необходимо замедлить падение диффузионного потенциала с ростом температуры, что должно привести к повышению общей эффективности СЭ при высоких температурах.

\section{Благодарности}

Авторы выражают благодарность заместителю генерального директора по научной работе НТЦ „Тонкопленочные технологии в энергетике“, доктору технических наук, профессору Е.И. Терукову за предоставленные образцы солнечных элементов НIT структур.

\section{Финансирование работы}

Работа выполнена при финансовой поддержке РФФИ и Рязанской области в рамках научного проекта № 18-42-623004 с использованием оборудования Регионального центра зондовой микроскопии коллективного пользования при Рязанском государственном радиотехническом университете им. В.Ф. Уткина. 


\section{Конфликт интересов}

Авторы заявляют, что у них нет конфликта интересов.

\section{Список литературы}

[1] M. Tanaka, M. Taguchi, T. Matsuyama, T. Sawada, S. Tsuda, S. Nakano, H. Hanafusa, Y. Kuwano. Jpn. J. Appl. Phys., 31, 3518 (1992).

[2] M.A. Green, E.D. Dunlop, J. Hohl-Ebinger, M. Yoshita, N. Kopidakis, A.W.Y. Ho Baillie. Prog. Photovolt. Res. Appl., 28, 3 (2020).

[3] M.Q. Khokhar, S.Q. Hussain, S. Kim, S. Lee, D.P. Pham, Y. Kim, E.-C. Cho, J. Yi. Trans. Electr. Electron. Mater., 21, 138 (2020).

[4] M. Lozac'h, S. Nunomura, H. Sai, K. Matsubara. Sol. Energy Mater. Sol. Cells, 185, 8 (2018).

[5] A. Descoeudres, C. Allebé, N. Badel, L. Barraud, J. Champliaud, G. Christmann, F. Debrot, A. Faes, J. Geissbühler, J. Horzel, A. Lachowicz. Sol. Energy, 175, 54 (2018).

[6] K. Yoshikawa. Sol. Energy Mater. Sol. Cells C, 173, 37 (2017).

[7] M.A. Green, Y. Hishikawa, E.D. Dunlop, D.H. Levi, J. HohlEbinger, M. Yoshita, A.W.Y. Ho-Baillie. Prog. Photovolt. Res. Appl., 27 (1), 3 (2019).

[8] K.C.N. Release. World's Highest Conversion Efficiency of $26.33 \%$ Achieved in a Crystalline Silicon Solar Cell. [Электронный pecypc] https://www.kaneka.co.jp/en/images/ topics/1473811995/1473811995_101.pdf

[9] S. Iftiquar, H. Park, S. Kim, J. Yi. Sol. Energy Mater. Sol. Cells, 204, 110238 (2020).

[10] Panasonic HIT® Solar Cell Achieves World's Highest Energy Conversion Efficiency of $25.6 \%$ at Research Level. [Электронный pecypc] https://news.panasonic.com/global/ press/data/2014/04/en140410-4/en140410-4.html

[11] Hanergy hits $25.11 \%$ efficiency with HJT cell. [Электронный pecypc] https://www.pv-magazine.com/2019/11/20/hanergysets-new-heterojunction-module-efficiency-record/

[12] Hanergy sets new efficiency record for heterojunction cell. [Электронный pecypc] https://www.pv-magazine.com/2019/ 08/08/hanergy-sets-new-efficiency-record-for-heterojunctionmodule/

[13] Y. Yao, X. Xu, X. Zhang, H. Zhou, X. Gu, S. Xiao. Mater. Sci. Semicond. Process., 77, 16 (2018).

[14] С.П. Вихров, Н.В. Вишняков, В.В. Гудзев, А.В. Ермачихин, Д.В. Жилина, В.Г. Литвинов, А.Д. Маслов, В.Г. Мишустин, Е.И. Теруков, А.С. Титов. ФТП, 52 (7), 787 (2018).

[15] А.В. Ермачихин, В.Г. Литвинов. ПТЭ, 2, 118 (2018).

[16] O. Maslova, A. Brezard-Oudot, M.E. Gueunier-Farret, J. Alvarez, W. Favre, D. Munoz, J.P. Kleider. Appl. Phys. Lett., 103, 183907 (2013).

[17] F. Recart, A. Cuevas. IEEE Trans. Electron Dev., 53, 442 (2006).

[18] D. Hinken, A. Milsted, R. Bock, B. Fischer, K. Bothe, M. Schütze, J. Isenberg, A. Schulze, M. Wagner. IEEE Trans. Electron Dev., 57, 2831 (2010).

[19] M. Schütze, D. Hinken, A. Milsted, M.B. Koentopp, Karsten Bothe. IEEE Trans. Electron Dev., 58, 3759 (2011).

[20] Olga Maslova, Thèse de doctorat. Capacitance spectroscopy in hydrogenated amorphous silicon Schottky diodes and high efficiency silicon heterojunction solar cells (Paris. Université Paris-Sud, 2013).
[21] A.S. Gudovskikh, S. Ibrahim, J.P. Kleider, J. Damon-Lacoste, P. Roca i Cabarrocas, Y. Veschetti, P.-J. Ribeyron. Thin Sol. Films, 515, 7481 (2007).

[22] C.A. Gueymard. Sol. Energy, 71 (5), 325 (2001).

[23] K. Pearson. Proc. Royal Soc. (London), 58, 240 (1895).

[24] M.H. Vishkasougheh, B. Tunaboylu. Energy Converse Management, 72, 141 (2013).

[25] ASTM International, ASTM G173-03 Standard AM0 and AM1.5 Spectra. USA, 250 (2003).

[26] K. Wakisaka,M. Taguchi, T. Sawada, M.Tanaka, T. Matsuyama, T. Matsuoka, S. Tsuda, S. Nakano, Y. Kishi, Y. Kuwano. Proc. 22nd IEEE Photovolt. Special. Conf. (Las Vegas, Nevada, 1991) v. 2, p. 887.

[27] M. Tanaka, M. Taguchi, T. Matsuyama, T. Sawada, S. Tsuda, S. Nakano, H. Hanafusa, Y. Kuwano. Jpn. J. Appl. Phys., 31, 3518 (1992).

[28] S.M. Iftiquar, Y. Lee, V.A. Dao, S. Kim, J. Yi. Materials and processes for energy: communicating current research and technological developments (Formatex Research Center, 2013) p. 59.

[29] C.-H. Hsu, X.-Y. Zhang, H.-J. Lin, S.-Y. Lien, Y.-S. Cho, C.S. Ye. Energies, 12 (13), 2541 (2019).

[30] L. Shen, F. Meng, Z. Liu. Sol. Energy, 97, 168 (2013)

[31] L. Harmatha, M. Mikolášek, L. Stuchlíková, A. Kósa, M. Žiška, L. Hrubčín, V.A. Skuratov. J. Electr. Eng., 66 (6), 323 (2015).

Редактор А.Н. Смирнов

\section{External quantum efficiency of bifacial HIT solar cells}

\section{A.V. Ermachikhin, Yu.V. Vorobyov, A.D. Maslov, E.P. Trusov, V.G. Litvinov}

Ryazan State Radio Engineering University, 390005 Ryazan, Russia

Abstract In this paper we showed that illumination of both front and back sides of heterojunction solar cells contribute efficiency. The obtained spectral dispersion of quantum efficiency confirms that contribution depends on conversion of short-wave photonts. The average difference between quantum efficiency of both sides is $\sim 11 \%$. Under standard solar illumination in the 400-1100 nm wavelength range the short-current density for front side is $36.3 \mathrm{~mA} / \mathrm{cm}^{2}$ and $32.7 \mathrm{~mA} / \mathrm{cm}^{2}$ for back side with reduction about $10 \%$. 